\title{
Super-adsorbent polyacrylate under swelling in water for passive solar control of building envelope
}

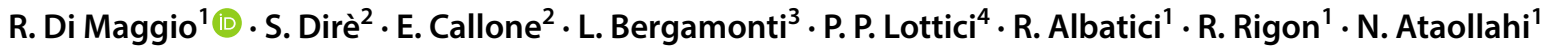

Received: 28 August 2019 / Accepted: 28 November 2019 / Published online: 7 December 2019

(c) Springer Nature Switzerland AG 2019

\begin{abstract}
Super-adsorbent polymers have the capacity to immobilize huge quantities of water in the form of hydrogel, thanks to their configuration. A commercial sodium polyacrylate (PA) was analysed as such and at different water uptakes, indicated through the weight ratios PA: $\mathrm{H}_{2} \mathrm{O}$. The hydrogels were prepared using different type of water (tap, distilled and deuterated) and characterized by Infrared and Raman spectroscopic analyses, nuclear magnetic resonance experiments, $\mathrm{CHN}$ elemental analysis, measurements of thermal conductivity and diffusivity. All the measurements were done in order to assess applications of PA: $\mathrm{H}_{2} \mathrm{O}$ gels as Thermal Energy Storage systems for improving thermal performances of building envelope through passive solar walls. It has been observed that the behaviour of the hydrogels depends both on temperature and water content. In certain conditions such as low weight ratios, a spontaneous and quick cooling of the hydrogel could be observed. The curves of heat flow and average specific heat $\left(c_{p}\right)$ were determined as a function of temperature in order to investigate the states of water in PA hydrogels. When a few water molecules are present, they are mainly and strongly bonded with carboxylate groups. Increasing the amount of water, greater shells of solvation around ionic groups form and water molecules can even interact with neighbouring non-polar hydrocarbon groups. At very high amount of water molecules, they are much more involved into $\mathrm{H}$-bonds among themselves, rather than with PA, so that water pools form into the links of polymeric network. Bulk-like water can freeze and melt. Whatever the amount of water in the hydrogel, its thermal capacity is higher than dry polymer, because the heat can be absorbed by the continuous desorption of water from polymer to bulk-like water ( water $_{\text {gel }} \rightarrow$ water $_{\text {liquid }}$ ), which can evaporate as temperature approaches $100^{\circ} \mathrm{C}$ ( water $_{\text {gel }} \rightarrow$ water $_{\text {liquid }} \rightarrow$ water $_{\text {vapour }}$ ).
\end{abstract}

Keywords Super-adsorbent polymers · Water-polymer interactions · Hydrogels thermal properties · Passive solar walls

\section{Introduction}

New laws and regulations have been recently introduced worldwide towards Nearly Zero energy building (NZeb) standard to decrease global energy consumption and greenhouse gas emissions, while maintaining a comfortable and healthy indoor environment [1]. Passive solutions are more and more considered, preventing the use of energy and the need to inform the users on the proper utilization of increasingly complex equipment, being their behaviour often responsible for the discrepancies between actual and theoretical energy consumption [2]. In this regards, passive thermal energy storage systems (TES) are often proposed because they help to maintain comfort conditions, minimizing the use of mechanical systems and exploiting natural heat energy sources [3], achieving

$\triangle$ R. Di Maggio, rosa.dimaggio@unitn.it | 'Department of Civil, Environmental and Mechanical Engineering, University of Trento, Via Mesiano 77, 38123 Trento, Italy. "2Klaus Müller" Magnetic Resonance Lab, Department of Industrial Engineering, University of Trento, Via Sommarive 9, 38123 Trento, Italy. ${ }^{3}$ Department of Chemistry, Life Sciences and Environmental Sustainability, University of Parma, Parco Area delle Scienze 17/A, 43124 Parma, Italy. ${ }^{4}$ Department of Mathematical, Physical and Computer Sciences, University of Parma, Parco Area delle Scienze 7/A, 43124 Parma, Italy. 
a possible space conditioning energy saving potential of about 10-15\% [4]. Among TES, due to the introduction of new materials, new control technologies and new computational and numerical simulation tools, there has been a renaissance of traditional building elements such as passive solar walls [5-8] and of proposals of different typologies of phase change materials (PCMs), often combined with passive solutions. PCMs are mainly paraffin and binary organic acids as well as inorganic or eutectics, used into building walls, roofs and floors [9-11]; they can also be used in passive solar collector-storage wall systems for improving their performance over the whole year [12] or mixed with other materials, mainly mortar [13] and cement [14] to enhance their performance. Furthermore, they can be encapsulated into special containers (tools of different shapes, shells or tubes) $[15,16]$ and integrated to building devices in order to reduce temperature fluctuations, to keep stable indoor conditions also improving the thermal comfort of occupants [11]. PCMs are considered latent heat storage devices (LH) because they transfer thermal energy while changing from solid to liquid, or liquid to solid, absorbing and releasing heat at a nearly constant temperature [15].

In recent years, there has been a considerable interest in water-swellable "super-adsorbent" polymers able of adsorbing and holding large amounts of water or other fluids, as well as releasing them. These polymers have previously found extensive commercial application as sorbents in personal care products $[17,18]$, materials for agricultural mulches [19] and matrices for controlled release devices [20].

Adsorbent polymers are most commonly formed by crosslinking polymerizations of hydrophilic acrylate or methacrylate monomers with small quantities of crosslinking agents containing two or more polymerizable double bonds [21]. Some of the commercially available polymers are terpolymers grafted with starch or polyvinyl alcohol [18]. The techniques described in the literature for preparing super-adsorbent polyacrylates (PA) are all aimed at adjusting their properties through the control of the network structure. Primarily, the elastic modulus of swollen gel increases and swelling capacity decreases with increasing cross-link density, which could be very low (about $0.03 \mathrm{~mol}$ of cross-linker per litre of dry polymer for diapers) in commercial super-adsorbent polymers. Conventional spectroscopic experiments, such as Fourier Transform InfraRed (FTIR) and Nuclear Magnetic Resonance (NMR) spectroscopy, can help in characterizing the cross-link density and especially in collecting relevant information on the interactions between polymer and water molecules.

More recently, the use of highly adsorbing materials was investigated to dampen indoor $\mathrm{RH} \%$ variations in museums or historical houses and in new evaporative cooling techniques $[22,23]$. In particular, PA exhibits an excellent moisture buffer performance, but also a hysteretic behaviour that may cause it get useless, losing its sorption properties $[22,23]$. Sodium polyacrylates can be more promising as adsorbing wet insulation layer in hybrid walls or roof, combining ventilated chambers and water evaporative cavities. Water evaporative systems are considered in direct and indirect cooling systems, because direct evaporation of water into an air stream causes its cooling.

In this regard, the hysteretic behaviour of commercial super-adsorbing PA must be understood in depth. In this paper, the results of a systematic evaluation of the thermal properties of PA-water systems are presented together with spectroscopic (NMR, Raman and FTIR) analyses in order to deeply investigate their physical and chemical interactions. The gels formed between PA and different types of water (tap, distilled and deuterated) were evaluated. This could help in both increasing the comprehension of mechanisms of super-adsorption of sodium polyacrylates and developing new latent or sensitive heat thermal energy storage units for building envelope.

\subsection{Experimental part}

A single batch of a commercial sodium polyacrylate (PA) has been used for all the experiments. The elemental content analysis was carried out by using an elementary analyzer CHN/S LECO. The elemental analysis of $\mathrm{C}, \mathrm{H}$ and, by difference, $\mathrm{O}$ of the dry powder is compatible with the polyacrylic nature of the material. The apparent density (tap density) of the PA powder is $0.73 \pm 0.02 \mathrm{~g} / \mathrm{ml}$. This was assessed using precision graded containers, filling and compacting the powder until no more slump of powder was observed. Except when specified, the polymer has not been dried, as its hygroscopicity would have led to the absorption of a quantity of water that could not be calculated in advance.

The hydrogels were obtained by mixing the PA powder with different types of water (tap water, distilled or deuterated) and labeled according to the weight ratio (PA: $\mathrm{H}_{2} \mathrm{O}(\operatorname{tap}), \mathrm{PA}: \mathrm{H}_{2} \mathrm{O}$ (distilled) and $\mathrm{PA}: \mathrm{D}_{2} \mathrm{O}$ ), which varies between 1:0 and 1:100. The average specific heat $\left(c_{p}\right)$ and calorimetric curves of both the powder as such and the gels were determined as a function of the temperature by using a DSC 92 SETARAM instrument (accuracy $0.1 \mathrm{~mW}$ ).

The conductivity and the thermal diffusivity (TPS $2500 \mathrm{~S}$ HotDisk) were measured on three PA forms: powder, tablet (obtained by pressing $1.3 \mathrm{~g}$ of the powder in a mold of $0.9 \mathrm{~cm}$ in diameter up to 4 tons) and gel $\mathrm{PA}: \mathrm{H}_{2} \mathrm{O}(\operatorname{tap})=1: 10$ at $22^{\circ} \mathrm{C}$. 
Fourier Transform Infrared (FT-IR) spectra were collected in Attenuated Total Reflection (ATR) mode with a Varian Excalibur 4100 (Varian Inc, Palo Alto, CA, USA) in the range $4000-550 \mathrm{~cm}^{-1}$ (32 scans, $2 \mathrm{~cm}^{-1}$ resolution).

Raman spectra were recorded in backscattering geometry with a Horiba-Jobin-Yvon LabRam micro-spectrometer (300 mm focal length, 1800 grooves/mm holographic grating, thermoelectrically cooled $1024 \times 256$ CCD) equipped with an Olympus BX40 microscope, with excitation at $473.1 \mathrm{~nm}$ of a doubled Nd:YAG solid state laser. Rayleigh radiation was blocked by an edge filter. The spectral resolution was about $1.5 \mathrm{~cm}^{-1}$. Spectra were collected using an ultra-long working distance $\times 50$ microscope objective. Typical exposures were 10-60 s, with 5-9 repetitions. The data analysis was performed by LabSpec software. Data processing was carried out by normalizing spectra to the integrated intensity of $\mathrm{CH}$ stretching bands.

NMR analyses were carried out with a Bruker 400WB spectrometer (Bruker Biospin, Billerica, MA, USA) operating at a proton frequency of $400.13 \mathrm{MHz}$. Solid state NMR spectra were acquired with $\mathrm{CP}$ pulse sequences under the following conditions: ${ }^{13} \mathrm{C}$ frequency: $100.48 \mathrm{MHz}$, $\pi / 2$ pulse $4.4 \mu \mathrm{s}$, decoupling length $5.9 \mu \mathrm{s}$, recycle delay: $4 \mathrm{~s}, 512$ scans, contact time $0.5 \mathrm{~ms}$. The contact time has been optimized in order to better evaluate the effect of PA interaction with water and to reduce the spin diffusion.
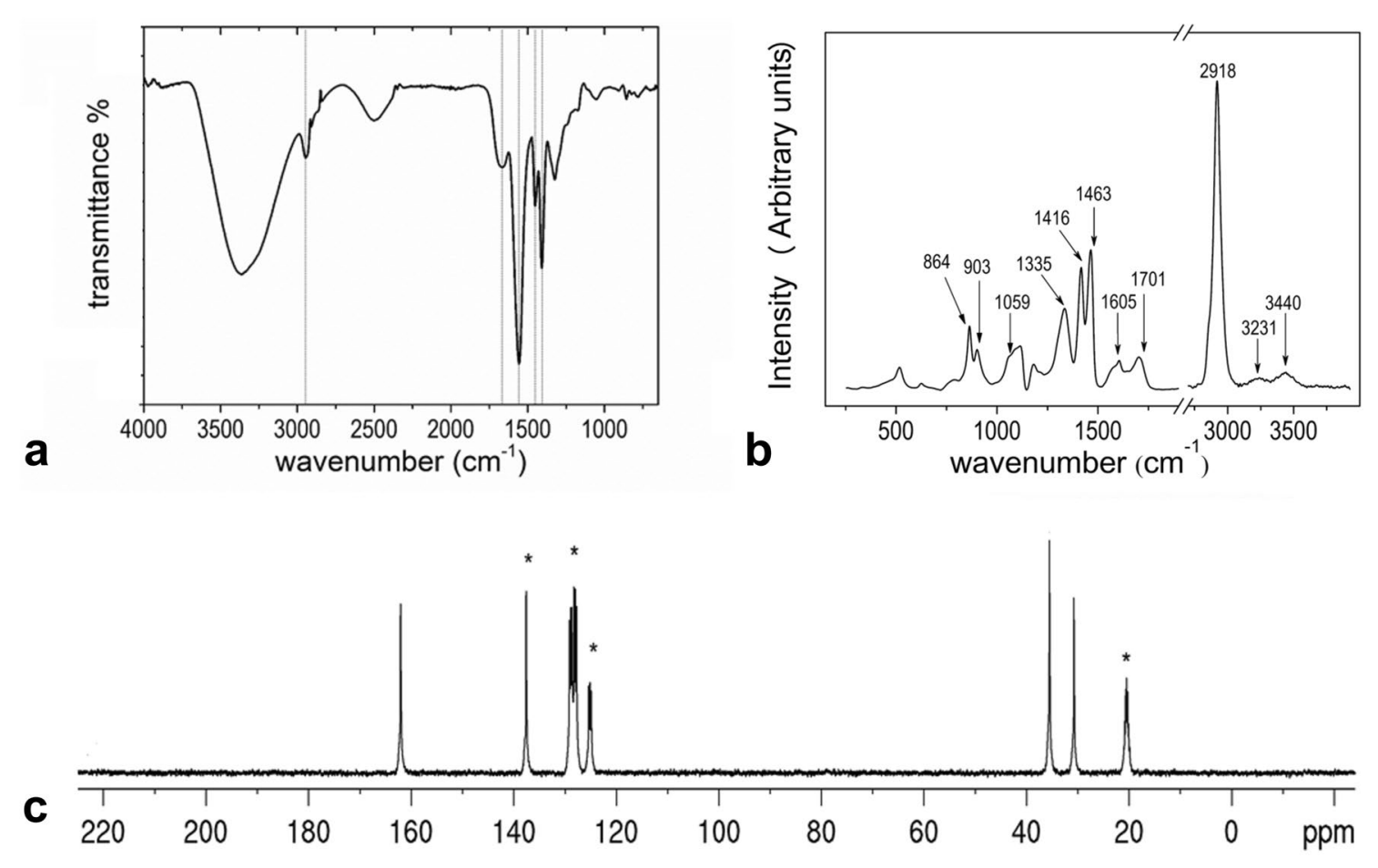

Fig. 1 FT-IR (a), Raman (b), and proton decoupled ${ }^{13} \mathrm{C}$ NMR (c) spectra of PA powder. In the FT-IR spectrum the peaks at 2945, 1660, 1554,1448 and $1404 \mathrm{~cm}^{-1}$ are indicated by grey lines. The NMR
The hydrogels were prepared by adding small amounts of water, for instrumental safety reasons. Samples were packed in $4 \mathrm{~mm}$ zirconia rotor and spun at $9 \mathrm{kHz}$ under air flow. Adamantane was used as external secondary reference. The hydrated PA samples were analysed also with proton decoupled ${ }^{13} \mathrm{C}$ liquid NMR (Bruker 400 Avance WB) equipped with $\mathrm{BBO} 5 \mathrm{~mm}$ probe, with the following conditions: $\pi / 47.2 \mu \mathrm{s}$, recycle delay $9 \mathrm{~s}, 2 \mathrm{k}$ scans. Moreover, ${ }^{1}$ H CPMG (Carr-Purcell-Meiboom-Gill) pulse sequence [24] was used for $t_{2}$ measurements (i.e. spin-spin relaxation times) with $\pi / 2$ pulse $5.4 \mu \mathrm{s}$, a $10 \mathrm{~ms}$ inter-pulse delay and 8 scans for 16 points. The hydrogels were prepared with selected $P A: \mathrm{D}_{2} \mathrm{O}$ ratios and in some cases were diluted in $\mathrm{d}_{8}$-toluene and $\mathrm{H}_{2} \mathrm{O}$ and analysed in $5 \mathrm{~mm}$ glass tubes.

\section{Results and discussion}

\subsection{PA powder}

The FT-IR spectrum of the PA powder (Fig. 1a) shows a strong band around $3371 \mathrm{~cm}^{-1}$ due to the stretching vibration of the hydroxyl groups from adsorbed water. The broad intense band centred at $1660 \mathrm{~cm}^{-1}$ is dominated by the $\mathrm{H}_{2} \mathrm{O}$ scissoring vibration, which hides the $\mathrm{C}=\mathrm{O}$ stretching band of the carboxylic group. The two bands at 1554

spectrum is recorded in $\mathrm{d}_{8}$-toluene and peaks marked with stars $\left(^{*}\right)$ are due to the solvent 
and $1404 \mathrm{~cm}^{-1}$ correspond, respectively, to the asymmetrical and symmetrical stretching vibrations of the carboxylate anion $\left(-\mathrm{COO}^{-}\right)[25-27]$. The bands at 2945, 1448 and $1325 \mathrm{~cm}^{-1}$ are due to the aliphatic backbones $\left(\mathrm{CH}_{2}\right.$ and $\mathrm{CH}$ stretching and bending vibrations). The broad band centred at $2486 \mathrm{~cm}^{-1}$ could be attributed to impurities of the commercial polyacrylate, since it disappears from the spectrum after washing the sample with toluene.

The Raman spectrum of dried PA powder (Fig. 1b) shows at 3231 and $3440 \mathrm{~cm}^{-1}$ the bands due to the $\mathrm{OH}$ stretching modes involved in strong and weak $\mathrm{H}$-bonds, respectively. In the range $2800-3000 \mathrm{~cm}^{-1}$, very strong peaks are present, due to $\mathrm{CH}_{2}$ and $\mathrm{CH}$ stretching vibrations of PA backbone. The characteristic feature of the carbonyl stretching belonging to the carboxylic group is found at $1701 \mathrm{~cm}^{-1}$, whereas stretching vibrations of the carboxylate group (-COO- $)$ are at $1605 \mathrm{~cm}^{-1}$. The peak due to $\mathrm{CH}_{2}$ deformations is at $1463 \mathrm{~cm}^{-1}$. The deformation of $\mathrm{CH}_{2}$ groups of the polyacrylate backbone shows a peak at $1416 \mathrm{~cm}^{-1}$, whereas that of $\mathrm{CH}$ groups bound to a carbonyl is at $1335 \mathrm{~cm}^{-1}$ [28]. The peaks at 903 and $864 \mathrm{~cm}^{-1}$ are attributable to the $\mathrm{C}-\mathrm{COOH}$ (with a contribution of the $\mathrm{OH}$ out of plane bending) and $\mathrm{C}_{-} \mathrm{COO}^{-}$stretching, respectively [29].

PA was also characterised by liquid NMR, although it is rather insoluble in common deuterated solvents: upon solvent adding a suspension was formed and poured into an NMR tube. Thus, the ${ }^{13} \mathrm{C}$ NMR spectrum recorded in $\mathrm{d}_{8}$-toluene and shown in Fig. $1 \mathrm{c}$ is due only to the soluble fraction [30]. Notwithstanding, the high-field resonances in PA spectrum, assigned to methylene (30.7 ppm) and methine (35.4 ppm) carbons, respectively and the peak at $162 \mathrm{ppm}$, assigned to $\mathrm{C}=\mathrm{O}$ functions [31] confirm the polyacrylate structure, in agreement with FT-IR and Raman data.

Three glass transitions are observed in the DSC curve of PA powder up $600{ }^{\circ} \mathrm{C}$ (here not shown): a first minor at about $30^{\circ} \mathrm{C}$; the most relevant between 80 and $100{ }^{\circ} \mathrm{C}$ and a third at about $220^{\circ} \mathrm{C}$. The two minor glass transitions are due to lateral chain or minor movements. A pronounced height of step indicates that the main chains are involved in glass transition, while the width of the step deals with homogeneity of the material, the larger the less homogeneous. This characterization appears useful in order to identify any material changes in PA supplies. In fact, polyacrylates synthesized upon same condition should show the same DSC pattern. It should be noted for a complete information that, at the end of each DSC test up to increasing maximum temperatures, a loss of mass was detected and shown in Table 1. That attributable to the evaporation of previously adsorbed humidity and to a small extent of volatile organic impurities, as suggested by FT-IR results, accounts for about $7 \%$. At temperatures
Table 1 PA mass losses measured after DSC tests at different maximum temperature with heating rate of $10^{\circ} \mathrm{C} / \mathrm{min}$ under a nitrogen atmosphere

\begin{tabular}{llll}
\hline $\mathrm{T}\left({ }^{\circ} \mathrm{C}\right)$ & $\begin{array}{l}\text { Initial weight } \\
(\mathrm{mg}) \pm 0.1\end{array}$ & $\begin{array}{l}\text { End weight } \\
(\mathrm{mg}) \pm 0.1\end{array}$ & Mass loss (\%) \\
\hline 100 & 27,6 & 26,4 & 4,4 \\
200 & 29,1 & 27,0 & 7,2 \\
300 & 22,3 & 21,1 & 5,3 \\
400 & 22,1 & 19,2 & 13,0 \\
500 & 21,5 & 12,5 & 41,9 \\
600 & 24,2 & 11,9 & 50,8 \\
\hline
\end{tabular}

above $200{ }^{\circ} \mathrm{C}$, polyacrylate is supposed to depolymerise through a pyrolytic mechanism, analogously to what is already known in the literature [32, 33].

\subsection{PA hydrogels}

PA adsorbs distilled and tap water about 1000 and 300 times its weight, respectively, to form a quasi-liquid hydrogel at $21{ }^{\circ} \mathrm{C}$ and R.H. $30 \%$. In both the cases, the adsorption was not homogeneous in the absence of mechanical mixing. During the step-by-step adsorption measurement, it has been observed a spontaneous cooling of the gel from 21 to $9{ }^{\circ} \mathrm{C}$, but increasing both mixing speed and water, the phenomenon is progressively reduced, until it does not occur at all. In fact, at the beginning water adsorption causes a prompt expansion of the polymer, a tough hydrogel forms and prevents the underlying material to adsorb further water in the absence of any mixing. The properties of the solutions depend on the way molecules arrange themselves and the nature/strength of the forces operating between them [34]. Non-polar parts of PA interact with polar ( $p$ ) and non-polar ( $n$ ) groups exclusively by London forces. The fugacity of small non-polar groups in water is greater, because the attractive forces between unlike groups are smaller than those corresponding to an ideal solution. As a consequence, the mixing of PA and water is endothermic and the final volume of the gel exceeds that of the unmixed components. PA is already known as water-lock agent due to its expansion in pipes or concrete.

Increasing the water content, stronger interactions become predominant, such as hydrogen bond, giving association or solvation according if it occurs among identical or unlike molecules, respectively. A regular solution is that when a solute is mixed in a completely random manner with solvent (e.g. ionic salts and water), but this is not the case of PA: $\mathrm{H}_{2} \mathrm{O}$ systems, in which polymeric molecules are much larger than those of water. Similarly to what Dashnau et al. discussed for water-glycerol mixture [35], when little water is present each strand of PA macromolecule may exist in many different configurations. 
Solvation is due to intermolecular forces among large dipole moments ( $p p=$ polar-polar) or to hydrogen bonding $(\mathrm{Hb})$ existing in solid-solid (ss) or solid-water (sw) interactions. Association phenomena are also due to nonpolar-nonpolar (nn) or nonpolar-polar (np) interactions, either solid-solid (intermolecular (ss) and intramolecular (ssi)) either solid-water (sw). PA macromolecules, surrounded by an increasing number of water molecules, can attain many more $\mathrm{np} / \mathrm{sw}$ and $\mathrm{pp} / \mathrm{sw}$ configurations than $\mathrm{nn} / \mathrm{ss}$ or ssi ones. The presence of even a small number of impurities reduces adsorption because water is engaged in solvation of common ions present in tap water, as well as the attractive forces $\mathrm{ssM}^{\mathrm{n}+}$ and $\mathrm{wM}^{\mathrm{n}+}$ prevent water from interacting massively and exclusively with PA macromolecules. As a consequence, the entropy excess (in excess of that which would prevail if the solution were ideal) reaches its maximum at lower amount of tap water, whereas the configurational freedom of PA macromolecules can benefit of much more amount of distilled water. Finally, when the water content approaches the PA adsorption limit, the water-water ( $w w$ ) interactions ( $\mathrm{pp}$ and $\mathrm{Hb}$ ) prevail.

In order to confirm the polymer changes upon water adsorption, FTIR experiments were performed on PA swollen in increasing amount of $\mathrm{D}_{2} \mathrm{O}$, which was used in place of $\mathrm{H}_{2} \mathrm{O}$ to reduce peak overlapping in the carbonyl region (Fig. 2). With increasing the amount of $\mathrm{D}_{2} \mathrm{O}$, the bands due to humidity decrease and modify in shape, whereas both the strong band assigned to $O-D$ stretching at $2470 \mathrm{~cm}^{-1}$ and O-D bending vibrations at $1205 \mathrm{~cm}^{-1}$ increase in intensity [36]. The reduction in intensity of the water scissoring vibration allows to appreciate the carbonyl stretching band, which is detected at $1696 \mathrm{~cm}^{-1}$ in $\mathrm{PA}: \mathrm{D}_{2} \mathrm{O}=1: 1$ and at $1710 \mathrm{~cm}^{-1}$ in $\mathrm{PA}: \mathrm{D}_{2} \mathrm{O}=1: 6$. (Fig. 2, Inset) [25]. Both asymmetric and symmetric stretching vibrations of the carboxylate group show a blue shift, from 1554 to $1568 \mathrm{~cm}^{-1}$ and from 1404 to $1413 \mathrm{~cm}^{-1}$, respectively. Interestingly, the $\mathrm{CH}_{2}$ bending vibration of the polymer backbone appears also modified in the $\mathrm{D}_{2} \mathrm{O}$-rich environment.

The effects on the Raman spectrum of the addition of tap water to PA have been investigated (Fig. 3a, b). As expected, main changes are observed for the features related to vibrations of the groups involved in $\mathrm{H}$-bonds $\left(-\mathrm{COO}^{-},-\mathrm{COOH}\right)$. The features corresponding to the deformation vibrations at $864 \mathrm{~cm}^{-1}$ due to the stretching of $\mathrm{C}-\mathrm{C}$ bond in $\mathrm{C}_{-} \mathrm{COO}^{-}$disappear just for the lowest $\mathrm{H}_{2} \mathrm{O}$ content, whereas that at $903 \mathrm{~cm}^{-1}$ involving $\mathrm{C}-\mathrm{COOH}$ increases slightly. It is likely that part of $-\mathrm{COO}^{-}$groups is protonated into the corresponding carboxylic group. Accordingly, also the peak at $1335 \mathrm{~cm}^{-1}$ reduces, becoming the shoulder of a growing peak at $1324 \mathrm{~cm}^{-1}$, attributable to $\mathrm{CH}$ close to $-\mathrm{COOH}$ groups. Moreover, the intensity of the band at $1416 \mathrm{~cm}^{-1}$ of $\mathrm{CH}_{2}$ groups increases due to $\mathrm{np} / \mathrm{sw}$ interactions with close water molecules [37]. It is worth noting that this peak increases in a limited way, differently from what occurs with other $\mathrm{pp} / \mathrm{sw}$ interactions. In fact, with increasing $\mathrm{H}_{2} \mathrm{O}$ content, the antisymmetric stretching vibration of the carboxylate anion shifts to lower wavenumbers, from 1605 to about $1560 \mathrm{~cm}^{-1}$ because of the formation of hydrogen bonds. The peak associated to the carbonyl stretching at $1701 \mathrm{~cm}^{-1}$ is hidden by the broad and intense band due to the bending water vibrations. It is worth noting that at low PA: $\mathrm{H}_{2} \mathrm{O}$ ratios it is visible the narrow peak of $\mathrm{O}_{2}$ (due to air trapped in gels and marked by asterisk in Fig. 3a). As it can be observed in Fig. 3b, no significant changes are found in $\mathrm{CH}_{2}$ and $\mathrm{CH}$ stretching vibrations of the backbone visible in $2800-3000 \mathrm{~cm}^{-1}$ range. The intensity of the $\mathrm{OH}$ stretching bands increases with water content: the peaks at 3231 and $3440 \mathrm{~cm}^{-1}$
Fig. 2 FTIR spectra of PA powder, and hydrogels with $P A: D_{2} \mathrm{O}$ ratio $1: 1$ and $1: 6$, respectively. The inset shows the magnification of the $1800-1000 \mathrm{~cm}^{-1}$ region (the spectra are normalised respect to the carboxylate asymmetric stretching band to highlight the $\mathrm{C}=\mathrm{O}$ stretching vibration)

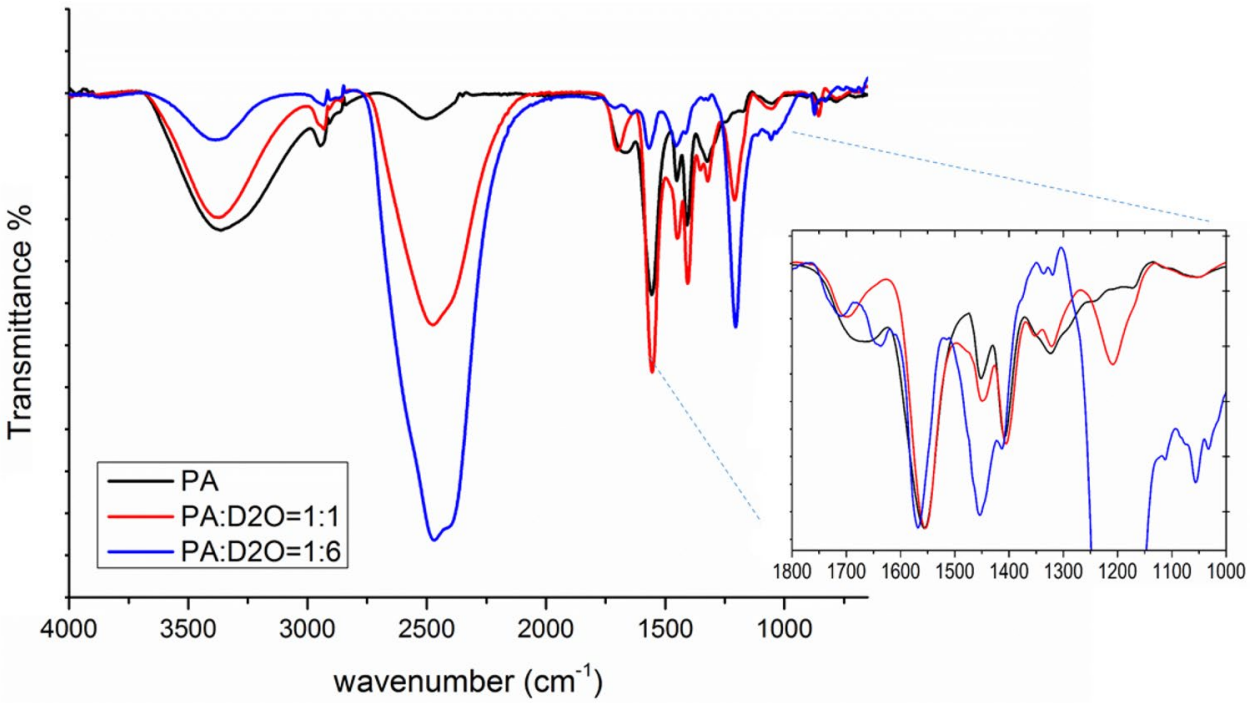

SN Applied Sciences A SPRINGER NATURE journa 
Fig. 3 Evolution of Raman spectra of PA with increasing tap water amounts in the range a $200-2000 \mathrm{~cm}^{-1}$ and $\mathbf{b}$ $2800-4000 \mathrm{~cm}^{-1}$, respectively

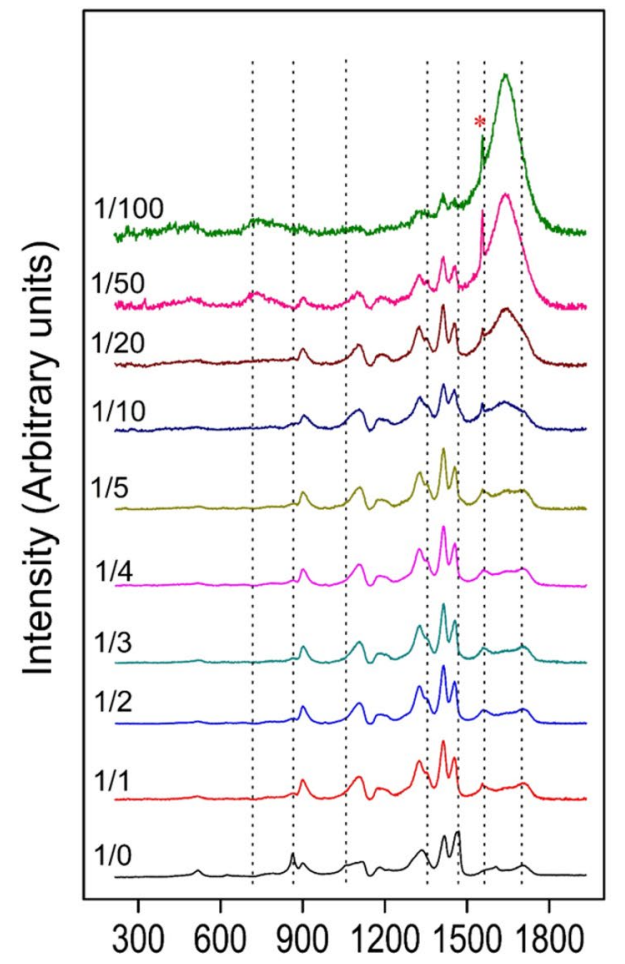

a Wavenumber $/ \mathrm{cm}^{-1}$

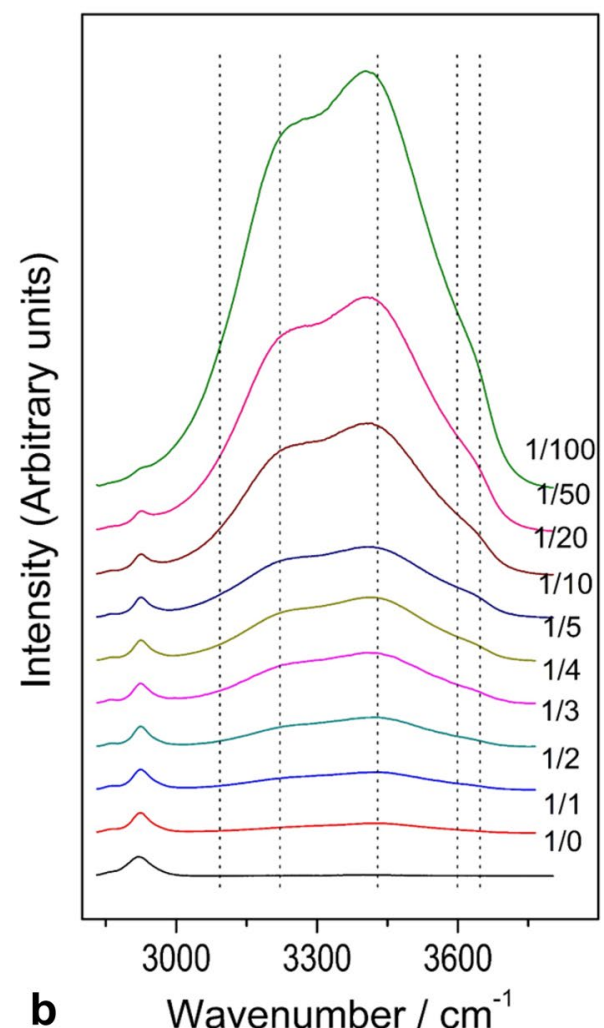

shift at lower wavenumber, already after the air moisture adsorption, whereas new peaks appear at about 3550 and $3600 \mathrm{~cm}^{-1}$.

The local environment affects the wavenumber of the $\mathrm{OH}$ stretching modes, because water can form with neighbouring molecules mainly $\mathrm{H}$ bonds both as proton donor (D) and as proton acceptor (A). According to the model proposed by Sun $[38,39]$, the $\mathrm{OH}$ stretching bands of water in the range $3000-3800 \mathrm{~cm}^{-1}$ of the Raman spectra are the result of the convolution of five sub-bands (e.g. DDAA, DDA, DAA, DA and free-OH), as shown in Fig. $4 a$. The two sub-bands DDAA and DA are the most intense contributions to the whole band in water solutions [40]. Minor configurations are, in order of importance, DDA,
DAA and free-water (free-OH). Therefore, the deconvolution of the spectra in the $2600-3900 \mathrm{~cm}^{-1}$ region into Gaussian peaks, also accounting for the stretching $\mathrm{CH}_{2}$ modes of the PA backbone, let to identify the contribution in the $\mathrm{OH}$ region of all the types of water molecules. As an example, a deconvolution is presented in Fig. $4 \mathrm{~b}$, normalized with respect to the intensity of $\mathrm{CH}_{2}$ stretching peak of PA powder, whose content is kept constant in the measurements.

This study showed that the positions of each peak follow a regular trend with increasing water content in the gels. In Fig. 5a the Raman shifts of free water, DA and DDAA contributions are shown. It is worth noting that for all the shifts the slope change occurs in the range
Fig. 4 a Different contributions to the $\mathrm{OH}$ band by deconvolution of the Raman spectrum measured on liquid water; $\mathbf{b}$ result of the deconvolution of the Raman spectrum for the ratio $\mathrm{PA}: \mathrm{H}_{2} \mathrm{O}=1: 1$
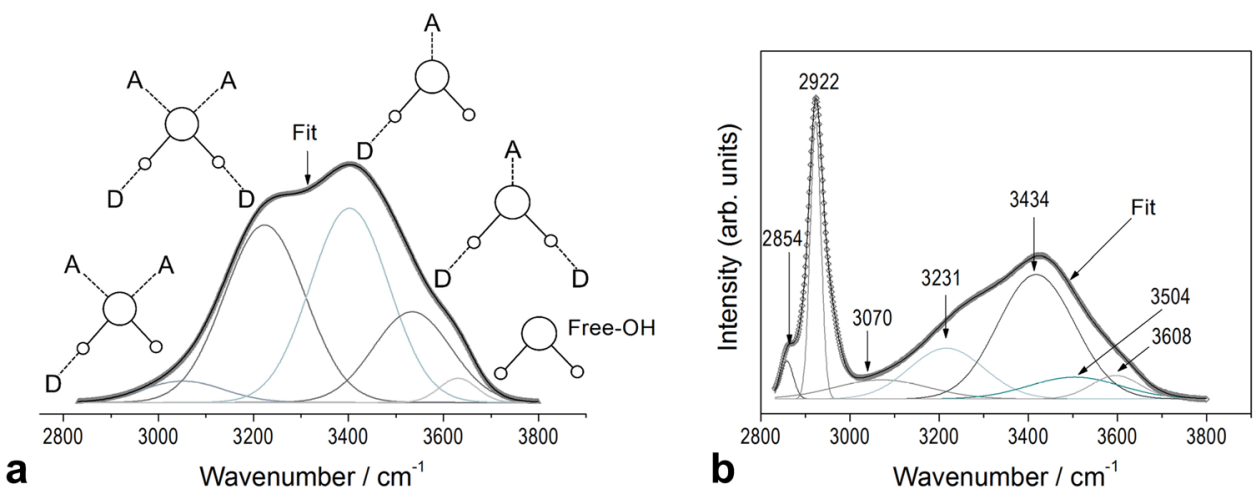

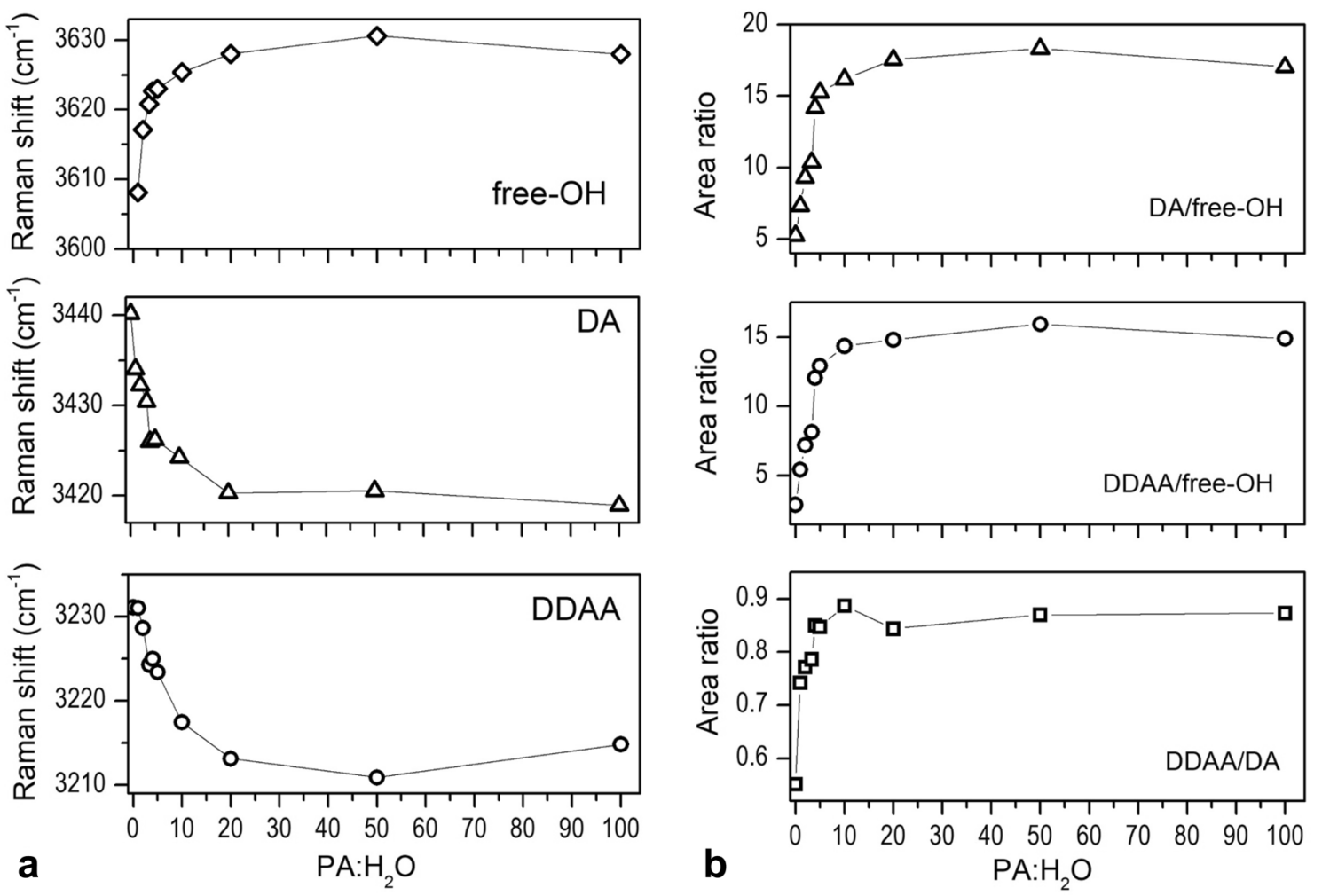

Fig. 5 a Raman shifts of free-OH, DA and DDAA sub-bands and $\mathbf{b}$ ratios of the sub-bands intensities (calculated by the areas from the deconvolution of Raman spectra) as a function of water content

1:10-1:20 of PA: $\mathrm{H}_{2} \mathrm{O}$ weight ratios. Moreover, increasing water content the contribution of the sub-bands DDAA and DA increases relatively to that of free-OH up to $P A: \mathrm{H}_{2} \mathrm{O}=1: 10$ (Fig. 5b). On the other hand, in the range from $\mathrm{PA}: \mathrm{H}_{2} \mathrm{O}=1: 1$ to $\mathrm{PA}: \mathrm{H}_{2} \mathrm{O}=1: 5$, the wavenumbers of the two sub-bands (DDAA and DA) decrease of more than $30 \mathrm{~cm}^{-1}$, confirming the formation of stronger hydrogen bonds. At higher water content the ratios between bound water and free- $\mathrm{OH}$ are nearly constant. It is even more interesting that also the DDAA/DA ratio increases with the same trend and reaches almost 0.9 at PA: $\mathrm{H}_{2} \mathrm{O}=1: 10$ and remains nearly constant at higher water content. Hence, it can be concluded that free-OH signals correspond to water molecules not involved in hydrogen bonds, but in interactions with the non-polar parts of PA backbone, whereas DA and DDAA peaks are peculiarities of bound water and bulk-like water, respectively. In the initial PA absorption process, water molecules first disrupt the intermolecular and intramolecular hydrogen bonds, then solvate its polar sites. These water molecules show a restricted mobility, because are strongly bound, uniformly throughout the polymer. Increasing water molecules, they preferentially form secondary or tertiary hydration shells, improving the number of hydrogen bonds, and also interact with non-polar part of the PA macromolecules (nn/sw), even if these can be easily desorbed. As the water further increases and approaches the equilibrium uptake amount, bulk-like water portion becomes more and more predominant.

Comparing the ${ }^{13} \mathrm{C}$ NMR spectrum of PA powder (Fig. 6a) with that of $\mathrm{PA}: \mathrm{H}_{2} \mathrm{O}=1: 0.2$ in $\mathrm{d}_{8}$-toluene (Fig. $6 \mathrm{~b}$ ), it can be noted that in the latter three weak and broad new signals appear, shifted downfield by 2 ppm due to the addition of water, which modifies the surroundings of the same functional groups. Moreover, two even broader peaks can be distinguished at 184 and $45.8 \mathrm{ppm}$. The former corresponds to a carboxylate functional group, and the latter to the neighbouring methine carbon. Accordingly, these two peaks represent the functional groups belonging to the polymer fraction that directly interacts with water. When the polymer is swollen in a very low amount of heavy water ( $P A: D_{2} O=1: 0.1$, Fig. $6 \mathrm{C}$ ), taking special care in mixing the two phases, the ${ }^{13} \mathrm{C}$ NMR spectrum shows the peaks due to the hydrated fraction of the acrylate and a further increase of $D_{2} O\left(P A: D_{2} O=1: 1\right.$, Fig. $\left.6 d\right)$ just reduces their broadening. As already observed for FTIR spectra (Fig. 2), the polymer-liquid interactions appear different using $\mathrm{H}_{2} \mathrm{O}$ and $\mathrm{D}_{2} \mathrm{O}$, probably due to the different strength of both van der Waals forces and $\mathrm{H}$-bonding. 
Fig. $6{ }^{13} \mathrm{C}$ NMR spectra of: a PA powder; b $\mathrm{PA}: \mathrm{H}_{2} \mathrm{O}=1: 0.2 ; \mathbf{c}$ $\mathrm{PA}: \mathrm{D}_{2} \mathrm{O}=1: 0.1 ; \mathbf{d} \mathrm{PA}: \mathrm{D}_{2} \mathrm{O}=1: 1$. Peaks marked with * are due to the solvent, $d_{8}$-toluene

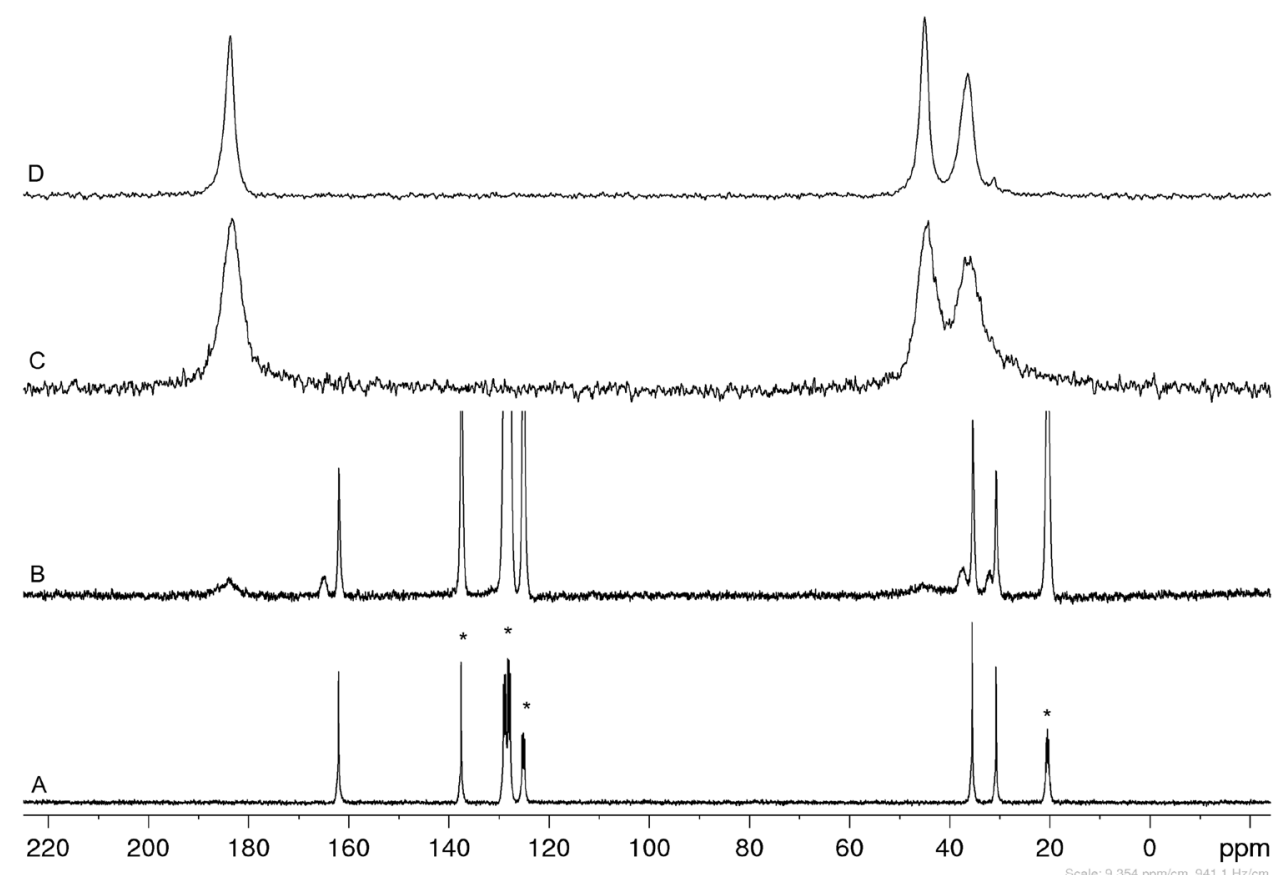

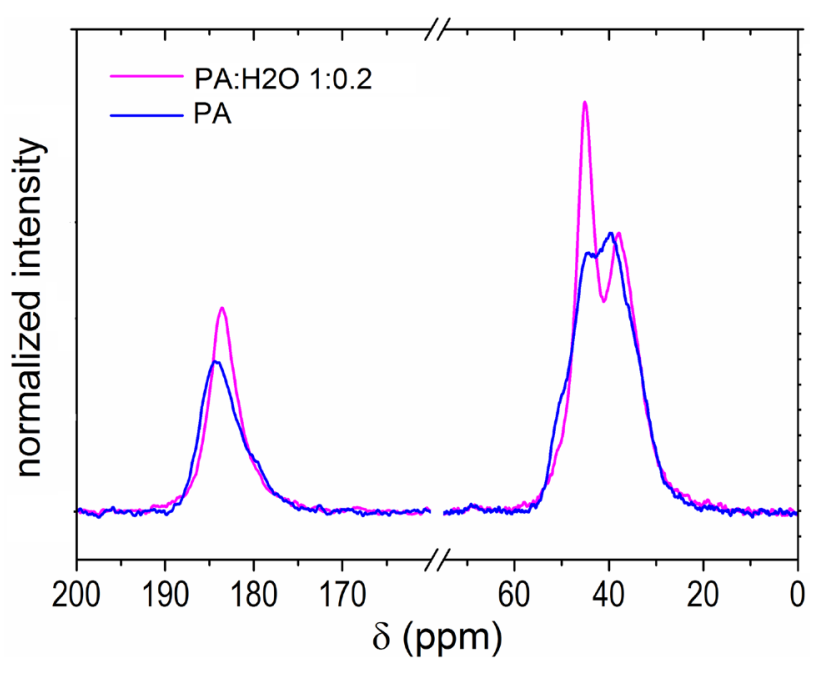

Fig. $7{ }^{13} \mathrm{C}$ CPMAS of PA powder and $\mathrm{PA}: \mathrm{H}_{2} \mathrm{O}=1: 0.2$

Moreover, sample PA: $\mathrm{H}_{2} \mathrm{O}=1: 0.2$ has been also studied with ${ }^{13} \mathrm{C}$ solid state NMR (Fig. 7). At the solid-state, PA is characterized by the $\mathrm{O}-\mathrm{C}=\mathrm{O}$ asymmetric peak at $183 \mathrm{ppm}$ and a complex resonance in the range 55-24 ppm resulting from the convolution of the peaks due to $\mathrm{CH}$ and $\mathrm{CH}_{2}$ carbon atoms of the polymer backbone. By comparison with the liquid spectrum (Fig. 1C), the peaks at 45.0 and $38.8 \mathrm{ppm}$ are assigned to $\mathrm{CH}$ and $\mathrm{CH}_{2}$ of the chain, whereas the left shoulder at $50.6 \mathrm{ppm}$ is due to branched quaternary sites $(\mathrm{Cq})$. The peaks at $34.7 \mathrm{ppm}$ can be attributed to the $\mathrm{CH}_{2}$ group adjacent to the methine carbon $\left(\mathrm{CH}_{2} \mathrm{v}\right)$. The results of the aliphatic region profile fitting analysis are summarized in Table 2.

According to the above assignments the degree of branching, calculated as $\mathrm{DB} \%=\mathrm{A}_{\mathrm{Cq}}{ }^{*} 100 /\left(\mathrm{A}_{\mathrm{Cq}}+\mathrm{A}_{\mathrm{CH}_{2}}\right)$, is about $12 \%$, meaning the crosslinking degree is quite high [41].

Mixing PA with water produces a marked change in the spectrum, increasing both the intensity and the sharpening of $-\mathrm{CH}$ and $-\mathrm{COO}^{-}$peaks with respect to the others. The comparison of the linewidths in Table 1 confirms that the $\mathrm{CH}$ peak experiences the highest sharpening upon water addition, due to the effect on the nearest neighbour carboxylate group. As a consequence, also the peaks of
Table 2 Profile fitting results of the aliphatic region: line widths (LW) and relative amounts (A\%) calculated form the ${ }^{13} \mathrm{C}$ CPMAS spectra

\begin{tabular}{|c|c|c|c|c|c|c|c|c|}
\hline \multirow{3}{*}{$\begin{array}{l}\delta(\mathrm{ppm}) \\
\text { Assign. }\end{array}$} & \multicolumn{2}{|l|}{50,6} & \multicolumn{2}{|l|}{45,1} & \multicolumn{2}{|l|}{39,6} & \multicolumn{2}{|l|}{34,7} \\
\hline & \multicolumn{2}{|l|}{$\mathrm{Cq}$} & \multicolumn{2}{|l|}{$\mathrm{CH}$} & \multicolumn{2}{|l|}{$\mathrm{CH}_{2}$} & \multicolumn{2}{|l|}{$\mathrm{CH}_{2} \mathrm{v}$} \\
\hline & $\mathrm{LW}(\mathrm{Hz})$ & $A \%$ & $\mathrm{LW}(\mathrm{Hz})$ & $\mathrm{A} \%$ & $\mathrm{LW}(\mathrm{Hz})$ & $A \%$ & LW (Hz) & $\mathrm{A} \%$ \\
\hline PA & 426,8 & 7,4 & 673,1 & 37,6 & 589,0 & 26,5 & 790,1 & 28,5 \\
\hline PA:H2O 1:0.2 & 595,0 & 7,4 & 450,3 & 36,0 & 655,0 & 30,9 & 759 & 23,8 \\
\hline
\end{tabular}


methylene groups linked to the methine carbons $\left(\mathrm{CH}_{2} \mathrm{v}\right)$ result sharper.

Focusing on the carboxylic region (Fig. 7), it can be noticed that the peak is not symmetric, but it clearly results from the overlapping of a sharp peak at $184 \mathrm{ppm}$, attributable to the carboxylate, and a shoulder at $180 \mathrm{ppm}$, due to the $-\mathrm{COOH}$, which are in ratio $72: 28$ according to the quantitative MAS experiment (not shown) [42]. The effect of the water addition is also pointed out by both the 1 -ppm upfield shift and the intensity increase of the main component of the $\mathrm{C}=\mathrm{O}$ resonance at $184 \mathrm{ppm}$.

The CPMAS experiment is very sensitive to the proton environment that surrounds a specific carbon, as already noticed. Thus, a substitution of $\mathrm{Na}^{+}$with water molecules in the proximity of an acrylate function will result in a significant increase of the related carbon resonance. As a matter of facts, according to the profile fitting of the $\mathrm{C}=\mathrm{O}$ resonance, the ratio $\mathrm{COO}^{-}: \mathrm{COOH}$ equal to $2: 1$ reaches the value 3:1 upon water addition. The reported signal changes suggest that the environment experienced by carboxylate and carboxylic groups is different because different is the strength of the interactions with water. The interaction of water with carboxylate anions via ion-dipole or more effective $\mathrm{Hb}$ results in a close proximity of $\mathrm{H}_{2} \mathrm{O}$ molecules and favours the cross polarization from water hydrogen to the closer carbon, leading to the marked intensity increase of the carboxylate component of the peak. This explains also the appearance of the carboxylate peak detected in
PA liquid NMR spectrum in $\mathrm{d}_{8}$-toluene upon water addition (Fig. 6b).

The effect of the PA-water interaction can be better evaluated by studying the water proton NMR spin-spin relaxation times $\left(t_{2}\right)$, which are usually measured to describe the water molecule dynamics in a specific environment [43]. To this aim, the sample PA in d-8 toluene with $\mathrm{PA}: \mathrm{H}_{2} \mathrm{O}=1: 0.2$ was considered, since its proton spectrum (not shown) shows a $\mathrm{H}_{2} \mathrm{O}$ peak well separated from the other resonances. The spin-spin relaxation curve of the water peak can be excellently fitted with two exponential decay components, resulting in two $t_{2}$ values of $39 \pm 2 \mathrm{~ms}$ accounting for about $68 \%$ and $113 \pm 7 \mathrm{~ms}$ accounting for the $32 \%$ of water molecules. In a very appreciable work, Traore et al. [43] found "three fractions" of waters in hydrated collagen characterized by different relaxation times that are related to the strength of the interaction with collagen chains. Following their discussion, in the present case it is possible to tentatively attribute the short $t_{2}$ to water molecules strongly bound to polar site on polymer and the long one to more mobile bound and bulk-like water, which is the minority in the case of low water content.

The existence of the different populations of water molecules with different interaction strength can be discussed also through thermal analysis. The calorimetric and the specific heat $\left(c_{p}\right)$ curves of the hydrogels are shown in Fig. $8 \mathrm{a}, \mathrm{b}$ as a function of temperature and water content. As discussed above, water molecules are predominately
Fig. 8 a Calorimetric curves and $\mathbf{b} c_{p}$ of dry PA and gels obtained mixing PA and increasing amount of tap water
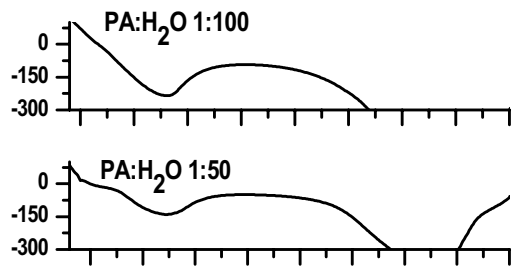

를

$\mathrm{PA}: \mathrm{H}_{2} \mathrm{O}$ 1:10

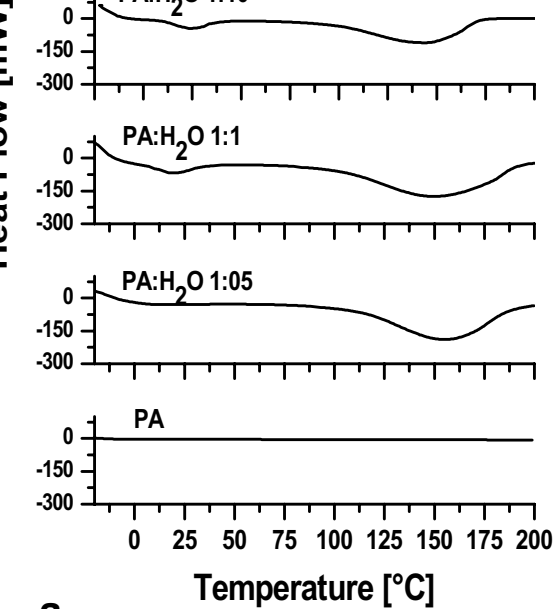

a

Temperature $\left[{ }^{\circ} \mathrm{C}\right]$
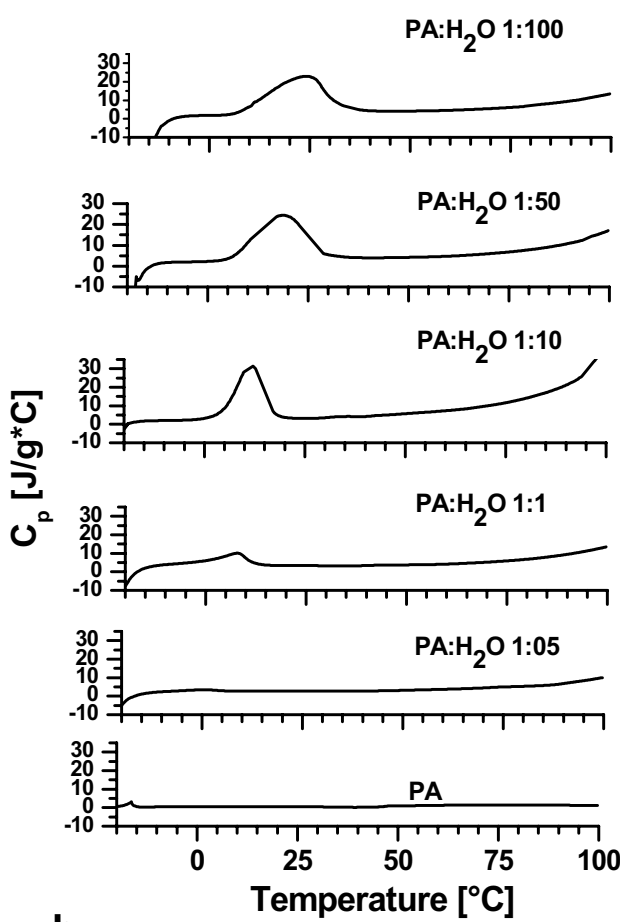

b 
as bulk-like decreasing the $\mathrm{PA}: \mathrm{H}_{2} \mathrm{O}$ ratio, so that two endothermic peaks of melting and evaporation of water are visible in heat flow curves. DSC curves exhibit a melting peak with a shoulder at low temperature, as a consequence of the crystallization of different types (bound and bulk-like) of water. Bulk-like water can freeze and melt. However, only the evaporation peak is visible in DSC curve of sample $\mathrm{PA}: \mathrm{H}_{2} \mathrm{O}=1: 0.5$, suggesting that the little water present is strongly linked to the polar groups of polymer. In general, the peaks shape and position are dependent on the amount of hydrogel used for the measurements, which was high, about $50 \mathrm{mg}$, for all of them. The freezing peaks are at temperature from 5 to $15^{\circ} \mathrm{C}$ lower than that of pure water, whereas the samples with the lowest amount of water do not show freezing peak at all, but a glass transition. The calorimetric curves of gels prepared with $\mathrm{D}_{2} \mathrm{O}$ and distilled water are almost overlapping to those of the corresponding gels with tap water.

Table 3 reports the mass losses and the heats calculated for each of the two peaks. First of all, at low water content the whole mass loss is greater than the added water, thus also organic volatile species are supposed to be released, in agreement with what already discussed. Moreover, it is worth noting the fusion heat is low with respect pure water. This confirms the existence of differently bound water molecules and just a part of them (bulk-like) can crystallize. Finally, the melting and evaporation heats increase with water content, but reach an equilibrium value (Table 3), much faster with tap water, more slowly

Table 3 Mass losses and enthalpy values measured during DSC runs for hydrogel with increasing water content

\begin{tabular}{|c|c|c|c|}
\hline Sample PA: $\mathrm{H}_{2} \mathrm{O}$ (tap) & $\begin{array}{l}\text { Mass loss up to } \\
200^{\circ} \mathrm{C}(\%)\end{array}$ & $\begin{array}{l}\text { Enthalpy- } \\
\text { firstpeak }(\mathrm{J} / \mathrm{g})\end{array}$ & $\begin{array}{l}\text { Enthalpy- } \\
\text { secondpeak } \\
(\mathrm{J} / \mathrm{g})\end{array}$ \\
\hline $1: 0.5$ & 43 & & -674 \\
\hline $1: 1$ & 58 & -65 & -836 \\
\hline $1: 10$ & 89 & -101 & -909 \\
\hline $1: 50$ & 96 & -162 & -1000 \\
\hline $1: 100$ & 99 & -171 & -1114 \\
\hline \multicolumn{4}{|l|}{$P A: D_{2} O$} \\
\hline $1: 0.5$ & 39 & & -331 \\
\hline $1: 1$ & 55 & -9 & -855 \\
\hline $1: 10$ & 90 & -74 & -968 \\
\hline $1: 50$ & 96 & -151 & -1241 \\
\hline $1: 100$ & 99 & -150 & -1329 \\
\hline \multicolumn{4}{|l|}{ PA: $\mathrm{H}_{2} \mathrm{O}$ (distilled) } \\
\hline $1: 0.5$ & 39 & & -488 \\
\hline $1: 1$ & 51 & -30 & -664 \\
\hline $1: 10$ & 92 & -62 & -1226 \\
\hline $1: 50$ & 98 & -69 & -1262 \\
\hline 1:100 & 99 & -52 & -1270 \\
\hline
\end{tabular}

with deuterated water and even more with distilled water. Finally, the samples prepared with tap water absorb the greatest heat for melting and the lowest for evaporation.

Analogously, in $c_{p}$ curves (Fig. 8b), the peaks of heat absorption corresponding to melting and evaporation of water are observed: they broaden and shift varying the water content. It is worth noting that the maximum value of thermal capacity occurs for $\mathrm{PA}: \mathrm{H}_{2} \mathrm{O}=1: 10$ at about $12{ }^{\circ} \mathrm{C}$. However, above $0{ }^{\circ} \mathrm{C}$ the thermal capacity of the gels is always greater than the dry PA powder. The heat can be absorbed and transferred in different ways: mainly vibrational in a gel (organic glass having very low viscosity), also rotational and translational in a liquid. When the thermal energy input into the gel lets all the vibrational states to maximum amplitude, each additional heat supplied must be accommodated differently. Rotational and translational degrees of freedom become available by releasing water. Thus, a desorption phenomenon (water from gel state to liquid state, water $_{\text {gel }} \rightarrow$ water $_{\text {liquid }}$ ) occurs. At low amount of water, very few molecules are available for desorption, given that the most are mainly and strongly bonded with ionic (carboxylate) groups. Increasing the amount of water in the gels, greater shells of solvation around ionic groups form and water molecules can even interact with neighbouring methine. These molecules could be easily desorbed. However, when gels approach the adsorption limit, water molecules are much more involved into $\mathrm{H}$-bonds among themselves, rather than with $\mathrm{PA}$, so that water pools (bulk-like water) form into the links of polymeric network. Further increasing the temperature, the heat input is so high that can be absorbed only by a continuous water desorption from the polymer to bulklike water ( water $_{\text {gel }} \rightarrow$ water $_{\text {liquid }}$ ), which can evaporate as the temperature approaches $100{ }^{\circ} \mathrm{C}$ ( water $_{\text {gel }} \rightarrow$ waterliquid $\rightarrow$ water $_{\text {vapour }}$ ). Basically, the measured specific thermal capacity would be a function of the enthalpies of the liquid water and the gel phase and of their relative abundance with respect to the total mass, including the polyacrylate which would have a semi-passive role. In fact, although apparently it does nothing, actually it contributes to establishing what is the specific reference enthalpy of the gel phase. When a system consists of a substrate (PA) and two interacting phases, $f$ (water) and $g$ (gel) which exchange matter conserving total enthalpy, its temperature is affected according to the following equation:

$c_{p}()=-\left(h^{f}()-h^{g}()\right)^{\frac{d \theta^{f}}{d T}}$

where $h()$ is the enthalpy of each phase $f$ and $g, \theta$ is the mass fraction. The equation needs to be improved taking into account the existence of different types of water within the gels and validated by experimental data. 


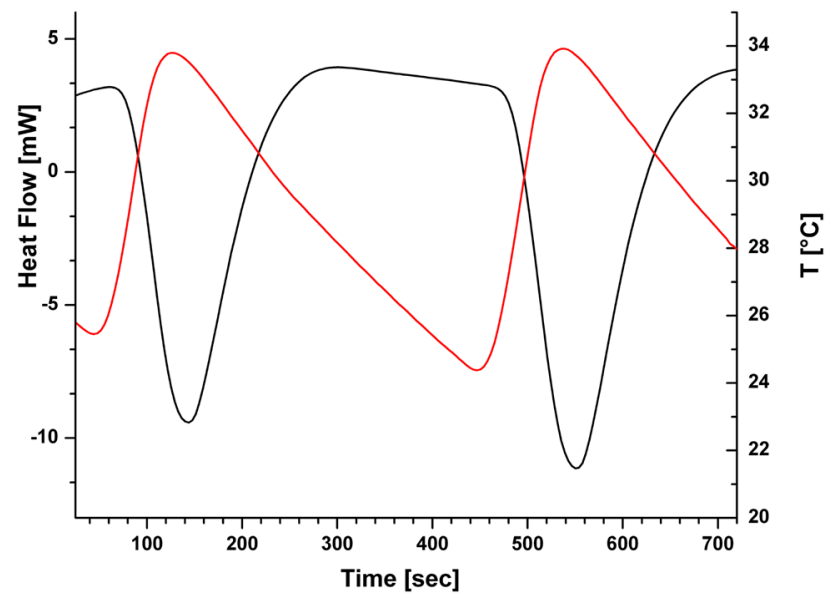

Fig. 9 Heat flow and Temperature versus time during a cyclic DSC test performed on $\mathrm{PA}: \mathrm{H}_{2} \mathrm{O}=1: 1$ (heating rate $=5^{\circ} \mathrm{C} / \mathrm{min}$ )

In a closed vessel in order to avoid evaporation, cyclic DSC tests were performed on gel samples with a heating rate of $5{ }^{\circ} \mathrm{C} / \mathrm{min}$, cooled and heated again in a fixed temperature range. As an example, the curve of heat flow versus time, during the test with $\mathrm{PA}: \mathrm{H}_{2} \mathrm{O}=1: 1$ between 24 and $34{ }^{\circ} \mathrm{C}$, is shown in Fig. 9. This suggests that, if the water remains confined, the material is able to absorb and release heat, again and again. Accordingly, a heat storage device, consisting of a closed circuit containing a certain amount of gel, can be designed and work cyclically in passive solar walls, for reducing energy consumption without reducing the comfort of buildings.

A material has to show a good balance between thermal capacity, conductivity and diffusivity, in order to be suitable as heat-storing element for passive solar-heating walls or as thermal energy storage unit. The two cases are more or less the same, although in the first one constraints, such as a thermal diffusion time $=12 \mathrm{~h}$ and wall thickness, need to be considered in calculating sizes and costs. At this regard, a high capacity is useless without a good heat transfer during charge/discharge cycle. Moreover, $\left(\kappa_{k} \rho\right)^{-\frac{1}{2}}$ or $\frac{\kappa}{\sqrt{a}}$ must be maximized, where $\kappa=$ thermal conductivity, $C_{p}=$ specific heat, $a=$ thermal diffusivity and $\rho=$ density [44]. Some values of conductivity and diffusivity were obtained at $22^{\circ} \mathrm{C}$ through the so-called Transient Plane Source (Hot Disk) measurement and are shown in Table 4. Actually, several tests on different gel states have been performed, showing that the data are critically dependent on the measurement conditions beside on the water content. As a matter of facts, the conductivity of the tablet is higher than that of powder and lower than that of the gel. It is worth noting that the values of $\left(\kappa C_{p} \rho\right)^{-\frac{1}{2}}$ or $\frac{\kappa}{\sqrt{a}}$ depend on water content and sample compactness.
Table 4 Thermal conductivity and diffusivity of three samples PA: $\mathrm{H}_{2} \mathrm{O}$

\begin{tabular}{lll}
\hline Sample PA: $\mathrm{H}_{2} \mathrm{O}$ & $\begin{array}{l}\text { Thermal conductivity } \\
(\mathrm{W} / \mathrm{mK})\end{array}$ & $\begin{array}{l}\text { Thermal } \\
\text { diffusivity } \\
\left(\mathrm{mm}^{2} / \mathrm{s}\right)\end{array}$ \\
\hline $1: 0$ (tablet) & $0.2262^{*}$ & $0.1687^{*}$ \\
& $0.2027^{\circ}$ & $0.1231^{\circ}$ \\
& $0.2077^{\#}$ & $0.1289^{\#}$ \\
$1: 0$ (powder) & $0.1468^{\complement}$ & $0.3936^{\varsigma}$ \\
& $0.1581^{\S}$ & $0.4623^{\S}$ \\
$1: 10$ (gel) & $0.7589^{\wedge}$ & $0.4289^{\wedge}$ \\
& $0.7497^{+}$ & $0.4343^{+}$ \\
& $0.7636^{>}$ & $0.4515^{>}$ \\
& $0.6530^{\&}$ & $0.2893^{\&}$ \\
\hline
\end{tabular}

Measurement conditions: ${ }^{*} 20 \mathrm{~mW} / 60 \mathrm{~s} / 0.581 ;{ }^{\circ} 10 \mathrm{~mW} / 160 \mathrm{~s} / 0.765$; \# $5 \mathrm{~mW} / 160 \mathrm{~s} / 0.813$

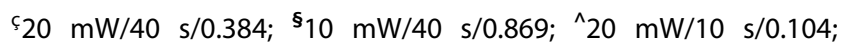
$+50 \mathrm{~mW} / 10 \mathrm{~s} / 0.106$

$>100 \mathrm{~mW} / 10 \mathrm{~s} / 0.110 ;{ }^{\&} 50 \mathrm{~mW} / 20 \mathrm{~s} / 0.141$

In order to design passive solar-heating walls, a calculation program is needed, performing the energy balance of a panel according to the solar radiation received and the actual weather conditions. The program should consider the phase transitions that occur and the material peculiarities. A model of the relation between the heat exchange among the involved phases and temperature has to be developed and able to fit the experimental data.

\section{Conclusions}

A commercial sodium polyacrylate (PA), usually used as super-adsorbent polymer, was analysed at different $\mathrm{PA}: \mathrm{H}_{2} \mathrm{O}$ weight ratios and prepared using different types of water (tap, distilled and deuterated). A spontaneous cooling can be observed in the hydrogel due to endothermal mixing of water molecules with non-polar parts of polymer. For each gel, the curves of heat flow and specific heat $\left(c_{p}\right)$ have been determined as a function of temperature and water content. The structural analysis based on NMR, FTIR and Raman results has been related to the different interactions that water molecules establish with polar and non-polar groups on PA. All the results underline that the behaviour of the polymer is strongly dependent on both temperature and water content. At low amount of water, molecules are mainly and strongly bonded with carboxylate groups. Increasing the water amount, greater shells of solvation around ionic groups form and water molecules can even interact with neighbouring non-polar hydrocarbon groups. Further increasing of water, molecules are much more involved into $\mathrm{H}$-bonds among themselves, 
rather than with $\mathrm{PA}$, so that bulk-like water pools form into the links of polymeric network. Bulk-like water can freeze and melt. However, a continuous desorption phenomenon (water ${ }_{\text {gel }} \rightarrow$ water $_{\text {liquid }}$ ) occurs and, increasing temperature, the heat input is so high that water evaporates (water gel $\rightarrow$ water $_{\text {liquid }} \rightarrow$ water $_{\text {vapour }}$ ). Thus, one of the most important results is that PA hydrogels can be considered in passive solar cooling of buildings both at low and high temperature, exploiting desorption and evaporation, respectively. It has been observed that heat absorption/ desorption could occur cyclically in a hydrogel with a low content of water is in a sealed vessel, in a range of temperature of interest for designing appropriately passive solar walls.

Further development is the proper design of the capsule/vessel system where gels will be stored, the characteristics and shape of the material for a capsule/vessel able to guarantee the gel behaviour with water over time. Soon after, laboratory analysis of in-scale products as well as of full-scale building elements in climatic chamber first, and on test cell in real boundary conditions afterwards, are necessary in order to define operational limits and the best position in the building envelope to fully exploit their behaviour (outside, inside, in the middle of walls and/or roofs). Finally, simple and effective instructions should be provided to designers along with a tool to properly size the PA-PCM system depending on the local climate, on the building use and on the construction technology and materials.

Acknowledgements Arch. P. Marcon and Mrs. W. Vaona are acknowledged for their suggestions.

Funding Funding was provided by Ministero dell'Istruzione, dell'Università e della Ricerca.

\section{Compliance with ethical standards}

Conflict of interest On behalf of all authors, the corresponding author states that there is no conflict of interest.

\section{References}

1. Ortiz MA, Kurvers SR, Bluyssen PM (2017) A review of comfort, health, and energy use: understanding daily energy use and wellbeing for the development of a new approach to study comfort. Energy Build 152:323-335

2. Hoes P, Hensen JLM, Loomans MG, Vries B, Bourgeois D (2009) User behaviour in whole building simulation. Energy Build 41:295-302

3. de Gracia A, Cabeza LF (2015) Phase change materials and thermal energy storage for buildings. Energy Build 103:414-419

4. Parameshwarana R, Kalaiselvamb S, Harikrishnanb S, Elayaperumala A (2012) Sustainable thermal energy storage technologies for buildings: a review. Renew Sustain Energy Rev 16:2394-2433
5. Bellos E, Tzivanidis C, Zisopoulou E, Mitsopoulos G, Antonopoulos KA (2016) An innovative Trombe wall as a passive heating system for a building in Athens-A comparison with the conventional Trombe wall and the insulated wall. Energy Build 133:754-769

6. Abbassi F, Dehmani L (2015) Experimental and numerical study on thermal performance of an unvented Trombe wall associated with internal thermal fins. Energy Build 105:119-128

7. Stazi F, Mastrucci A, di Perna C (2012) Trombe wall management in summer conditions: an experimental study. Sol Energy 86:2839-2851

8. Hami K, Draoui B, Hami O (2012) The thermal performances of a solar wall. Energy 39:11-16

9. Mengjie S, Fuxin N, Mao Ning H, Yanxin DS (2018) Review on building energy performance improvement using phase change materials. Energy Build 158:776-793

10. Wang Y, Xia TD, Feng HX, Zhang H (2011) Stearic acid/polymethylmethacrylate composite as form-stable phase change materials for latent heat thermal energy storage. Renew Energy 36:1814-1820

11. Akeiber $H$, Nejat $P$, Majid MZA, Wahid MA, Jomehzadeh $F$, Famileh IZ, Calautit JK, Hughes BR, Zaki SA (2016) A review on phase change material (PCM) for sustainable passive cooling in building envelopes. Renew Sustain Energy Rev 60:1470-1497

12. Sun $D$, Wang $L$ (2016) Research on heat transfer performance of passive solar collector-storage wall system with phase change materials. Energy Build 119:183-188

13. hua Tian G, lin Lv H, en Huang J, Liu P, Feng W (2017) Experimental study on the thermal performance of a wall coated with a phase-change, energy-storing mortar layer during summer. Appl Therm Eng 124:279-285

14. Zhang Q, Rao Y, Jiao Y, Li L, Li Y, Jin L (2017) Preparation and performance of composite building materials with phase change materials for thermal storage. Energy Procedia 143:125-130

15. Jeon J, Lee JH, Seo J, Jeong SG, Kim S (2013) Application of PCM thermal energy storage system to reduce building energy consumption. J Thermal Anal Calorim 111:279-288

16. Fredi G, Dirè S, Callone $E$, Ceccato R, Mondadori F, Pegoretti A (2019) Docosane-organosilica microcapsules for structural composites with thermal energy storage/release capability. Materials 12:1286

17. Masuda F (1994) Trends in the development of superabsorbent polymers for diapers, Chapter 7. In: Buchholz FL, Peppas NA (eds) Superadsorbent polymers, ACS symposium series, vol 573. American Chemical Society, Washington, DC, pp 88-98

18. Buchholz FL (1990) In: Brannon-Peppas L, Harland RS (eds) In adsorbent polymer technology. Elsevier Science Publishing Company Inc., New York

19. Kazanskii KS, Dubrovskii SA (1992) Adv Polym Sci 104:97

20. Colombo $P(1993)$ Swelling-controlled release in hydrogel matrices for oral route. Adv Drug Deliv Rev 11:37-57

21. Gooch JW (2011) Super adsorbent fibers. In: Gooch JW (ed) Encyclopedic dictionary of polymers. Springer, New York

22. Cerolini S, D'Orazio M, Di Perna C, Stazi A (2009) Moisture buffering capacity of highly adsorbing materials. Energy Build 41:164-168

23. Naticchia B, D'Orazio M, Carbonari A, Persico I (2010) Energy performance evaluation of a novel evaporative cooling technique. Energy Build 42:1926-1938

24. Meiboom S, Gill D (1958) Modified spin-echo method for measuring nuclear relaxation times. Rev Sci Instrum 29:688-691

25. Lee DH, Condrate RA, Reed JS (2009) Infrared spectral investigation of polyacrylate adsorption on alumina. J Mater Sci $31: 471-478$

26. Socrates G (2004) Infrared and Raman characteristic group frequencies: tables and charts, 3rd edn. Wiley, Chichester 
27. Burikov S, Dolenko T, Patsaeva S, Starokurov Y, Yuzhakov V (2010) Raman and IR spectroscopy research on hydrogen bonding in water-ethanol systems. Mol Phys 108(18):2427-2436

28. Grabowska B, Olejnik MSE, Kaczmarska K, Tyliszczak B (2015) FT-IR and FT-Raman studies of cross-linking processes with $\mathrm{Ca}^{2+}$ ions, glutaraldehyde and microwave radiation for polymer composition of poly(acrylic acid)/sodium salt of carboxymethyl starch-in moulding sands, Part II. Spectrochim Acta Part A Mol Biomol Spectrosc 151:27-33

29. Dong J, Ozaki Y, Nakashima K (1997) Infrared, Raman, and Nearinfrared spectroscopic evidence for the coexistence of various hydrogen-bond forms in poly(acrylic acid). Macromolecules 30:1111-1117

30. Stothers JA, Lauterbur PC (1964) C13 Chemical shifts in organic carbonyl groups. Can J Chem 42:1563-1576

31. Ullah F, Othman MBH, Javed F, Ahmad Z, Akil H (2015) Classification, processing and application of hydrogels: a review. Mater Sci Eng C 57:414-433

32. McNeill IC, Sadeghi SMT (1900) Thermal stability and degradation mechanisms of poly(acrylic acid) and its salts: part 2-Sodium and potassium salts. Polymer Degrad Stab 30(2):213-230

33. Di Maggio R, Fambri L, Mustarelli P, Campostrini R (2012) Physico-chemical characterization of hybrid polymers obtained by 2-hydroxyethyl(methacrylate) and alkoxides of zirconium. Polymer 44(24):7311-7320

34. Della Volpe C, Siboni S (2001) The evaluation of electron-donor and electron-acceptor properties and their role in the interaction of solid surfaces with water. In: Morra M (ed) Water in biomaterials surface science. Wiley, Chichester, pp 183-214

35. Dashnau JL, Nucci NV, Sharp KA, Vanderkooi JM (2006) Hydrogen bonding and the cryoprotective properties of glycerol/ water mixtures. J Phys Chem B 110:13670-13677
36. Walrafen GE (1972) Raman and infrared spectral investigations of water structure. In: Franks $F$ (ed) The physics and physical chemistry of water. Water (a comprehensive treatise), vol 1. Springer, Boston, pp 151-214

37. Todica M, Stefan R, Pop CV, Olar L (2015) IR and raman investigation of some poly(acrylic) acid gels in aqueous and neutralized state. Acta Phys Pol A 128:128-135

38. Sun $Q$ (2009) The Raman $\mathrm{OH}$ stretching bands of liquid water. Vib Spectrosc 51:213-217

39. Sun Q (2013) Local statistical interpretation for water structure. Chem Phys Lett 568-569:90-94

40. Choe CS, Lademann J, Darvin ME (2016) Depth profiles of hydrogen bound water molecule types and their relation to lipid and protein interaction in the human stratum corneum in vivo. Analyst 141:6329-6337

41. Castignolles $P$, Graf R, Parkinson $M$, Wilhelm M, Gaborieau M (2009) Detection and quantification of branching in polyacrylates by size-exclusion chromatography (SEC) and meltstate 13C NMR spectroscopy. Polymer 50:2373-2383

42. Candau F, Zekhnini Z, Heatley F, Franta E (1986) Characterization of poly(acrylamide-co-acrylates) obtained by inverse microemulsion polymerization. Colloid Polymer Sci 264:676-682

43. Traore A, Focaut L, Renou JP (2000) H-1-NMR study of water dynamics in hydrated collagen: transverse relaxation-time and diffusion analysis. Biopolymers 53:476-483

44. Ashby MF (2005) Materials selection in mechanical design, 3rd edn. Oxford press, Oxford, p 2005

Publisher's Note Springer Nature remains neutral with regard to jurisdictional claims in published maps and institutional affiliations. 